\title{
A Novel Fusarium Species Causes a Canker Disease of the Critically Endangered Conifer, Torreya taxifolia
}

Jason A. Smith, School of Forest Resources and Conservation, University of Florida, Gainesville; Kerry O'Donnell, Bacterial Foodborne Pathogens and Mycology Research Unit, Agricultural Research Service, U.S. Department of Agriculture, Peoria, IL; Lacey L. Mount, Department of Plant Pathology, University of Florida, Gainesville; Keumchul Shin, Kelly Peacock, and Aaron Trulock, School of Forest Resources and Conservation, University of Florida, Gainesville; Tova Spector, Florida Park Service, Department of Environmental Protection, Panama City; and Jenny Cruse-Sanders and Ron Determann, Atlanta Botanical Garden, Atlanta, GA

\begin{abstract}
Smith, J. A., O’Donnell, K., Mount, L. L., Shin, K., Peacock, K., Trulock, A., Spector, T., Cruse-Sanders, J., and Determann, R. 2011. A novel Fusarium species causes a canker disease of the critically endangered conifer, Torreya taxifolia. Plant Dis. 95:633-639.

A canker disease of Florida torreya (Torreya taxifolia) has been implicated in the decline of this critically endangered species in its native range of northern Florida and southeastern Georgia. In surveys of eight Florida torreya sites, cankers were present on all dead trees and 71 to $100 \%$ of living trees, suggesting that a fungal pathogen might be the causal agent. To identify the causal agent, nuclear ribosomal internal transcribed spacer region (ITS rDNA) sequences were determined for 115 fungi isolated from cankers on 46 symptomatic trees sampled at three sites in northern Florida. BLASTn searches of the GenBank nucleotide database, using the ITS rDNA sequences as the query, indi-

cated that a novel Fusarium species designated Fsp-1 might be the etiological agent. Molecular phylogenetic analyses of partial translation elongation factor 1-alpha $(E F-1)$ and RNA polymerase second largest subunit $(R P B 2)$ gene sequences indicate that Fsp-1 represents a novel species representing one of the earliest divergences within the Gibberella clade of Fusarium. Results of pathogenicity experiments established that the four isolates of Fsp-1 tested could induce canker symptoms on cultivated Florida torreya in a growth chamber. Koch's postulates were completed by the recovery and identification of Fsp-1 from cankers of the inoculated plants.
\end{abstract}

Canker disease of Florida torreya, known as gopherwood or stinking cedar (Torreya taxifolia Arn.), hereafter referred to as CDFT, appears to have contributed to this plant being listed as critically endangered by the U.S. Fish and Wildlife Service. Currently, this endemic taxaceous conifer is restricted to bluffs and ravines along the Apalachicola River in Gadsden and Liberty counties in Florida and Decatur County in Georgia (16). T. taxifolia is considered the rarest conifer in North America and one of the most endangered species in the world (4).

Although the decline of Florida torreya was first observed in the late 1930s (1), the tree was still common in its habitat in northern Florida and southeastern Georgia through the 1950s. The rapid decline of the species in the early 1900s was initially attributed to an unknown fungal disease based on the abundance of leaf spots and stem cankers (7). Due to decline, and to the lack of seed-bearing trees (1), Florida torreya was considered to be destined for extinction (7). In addition to the decline, this species has been negatively impacted by changes in hydrology, forest structure, heavy deer browse, and a loss of reproductive capability (17). Florida torreya stems killed by disease often re-sprout in a manner reminiscent of American chestnut following Chestnut Blight. Florida torreya has declined by more than $99 \%$ over the past century from an estimated population of 357,500 individuals in 1914 to approximately 1,350 in the 1990 s $(19,20)$, to current estimates of 400 to 600 individuals (T. Spector, personal communication). Trees in their native range have not reproduced from seed for several decades (18). Despite several attempts to conclusively determine the causal agent of Florida torreya decline, disease etiology has not been elucidated $(1-3,8,22)$. In the first pathology studies conducted on T. taxifolia (1), it was noted that leaf spots, needle necrosis,

Corresponding author: Jason A. Smith, E-mail: jasons@ufl.edu

Accepted for publication 26 January 2011.

doi:10.1094/PDIS-10-10-0703

(C) 2011 The American Phytopathological Society defoliation, and stem lesions were common on native and cultivated T. taxifolia. Several pathogens were commonly isolated from symptomatic needles (Macrophoma sp., Rhizoctonia solani, Sphaeropsis sp., and Sclerotium rolfsii); however, no pathogens were isolated from cankered stems and Koch's postulates were not completed. Subsequently, El-Gholl (3) reported Fusarium lateritium as a causal agent by demonstrating this species' capacity to cause leaf spots. Alfieri et al. (2) completed Koch's postulates with F. lateritium as a leaf spot pathogen, but did not address whether this species could induce the canker disease. While Schwartz et al. (22) implicated Pestalotiopsis microspora as the causal agent of the canker disease, no information was given on canker development, morphology, or ability to cause mortality. Artificial inoculations using $P$. microspora resulted in stem canker development (8), but stem mortality was not observed. These reports are considered to be inconclusive given that Pestalotiopsis spp. are considered to be weak opportunistic pathogens (23). Subsequent studies implicated a Scytalidium sp. due to frequent isolation from cultivated and naturally occurring Florida torreya. Artificial inoculations resulted in small lesions on needles, but cankers were not observed.

In addition to biotic causes of decline, several studies have reported on changes in soils, drought, global warming, sunlight exposure, and fire regime as possible causes of decline (21). Some of these environmental changes are thought to have occurred because of the building of the Woodruff Dam along the Apalachicola River in 1957, and changing land uses in the surrounding areas. However, none of these environmental hypotheses has been demonstrated as a cause of the decline.

Current efforts to manage this endangered species have been hindered by a lack of understanding of the current and historic causes of disease of Florida torreya. As a result, various agencies have taken different approaches to manage Florida torreya depending on which cause the decline is attributed to. For these reasons, more information is needed about the etiology of CDFT in order to develop sound management practices. Accordingly, the present study was conducted to: (i) assess canker incidence among natural populations of T. taxifolia, and (ii) identify the causal agent of CDFT. 


\section{Materials and Methods}

Field surveys. During 2008 to 2010, surveys were conducted for all living T. taxifolia on public and private lands in Gadsden and Liberty counties in Florida where this species had been reported previously. Surveys were conducted using historical maps/data, personal knowledge of the sites, and visual searching. Once located, individual trees were measured for height and diameter at ground line (DGL). Due to stem heights commonly $<1 \mathrm{~m}$, diameter at breast height could not be measured for most specimens. The condition of each tree and occurrence of stem cankers was recorded. Position on slope, soil conditions, associated flora, occurrence of leaf spots and canopy cover/light intensity were also recorded. For canker incidence, site means were analyzed using oneway analysis of variance (ANOVA) and Duncan's multiple range test $(P<0.05)$ (SAS ver. 9.1$)$.

Isolation and tentative identification of fungi. Stem tissue from the margins of 150 cankers were collected in the field from 46 diseased trees collected from three locations and returned to the laboratory. Samples were cut to approximately $10 \mathrm{~mm}^{2}$ and surface sterilized in 5\% sodium hypochlorite for $30 \mathrm{~s}$, followed by a 10-s rinse in sterile $\mathrm{H}_{2} \mathrm{O}$. The samples were placed on $2 \%$ potato dextrose agar (PDA; DIFCO, Detroit, MI) and incubated at room temperature for 5 to 7 days. Fungal colonies were then subcultured on PDA for subsequent identification and inoculation experiments.

A total of 129 isolates were used for identification based on ribosomal internal transcribed spacer region (ITS-rDNA) sequences. DNA was extracted using the Qiagen DNeasy Plant Mini kit (Qiagen Inc., Valencia, CA) following the manufacturer's instructions except that samples were ground using liquid nitrogen and a mortar and pestle prior to extraction, and the $65^{\circ} \mathrm{C}$ incubation step was increased to $1 \mathrm{~h}$. PCRs using the universal primers ITS1 and ITS4 (26) were performed with the following reaction mixture: $1 \mu \mathrm{l}$ of diluted (1:100) template DNA, $1 \mu \mathrm{l}$ of each primer $(10 \mu \mathrm{M})$, $9.5 \mu \mathrm{l}$ of $\mathrm{ddH}_{2} \mathrm{O}$, and $12.5 \mu \mathrm{l}$ of Amplitaq Gold Master Mix (Applied Biosystems, Emeryville, CA). PCRs were performed in a MJ Mini thermocycler (BioRad Inc., Hercules, CA) with the following thermocycling profile: $94^{\circ} \mathrm{C}$ for $5 \mathrm{~min}$ followed by 35 cycles of $94^{\circ} \mathrm{C}$ for $1 \mathrm{~min}, 55^{\circ} \mathrm{C}$ for $1 \mathrm{~min}, 72^{\circ} \mathrm{C}$ for $1 \mathrm{~min}$, followed by a final extension step at $72^{\circ} \mathrm{C}$ for $5 \mathrm{~min}$. PCR amplicons were visualized on a $1.5 \%$ agarose gel and were purified prior to sequencing using the EXOSAPit kit (USB Corp., Cleveland, OH). Amplicons were sequenced at the University of Florida Interdisciplinary Center for Biotechnology Research using an ABI3730 DNA Analyzer (Applied Biosystems Inc., Foster City, CA). Forward and reverse sequences were edited and contigs were aligned using ChromasPro ver. 1.5 software (Technelysium Inc., Tewantin QLD, Australia). Edited sequences were used for BLASTn searches of the GenBank nucleotide database (http://www.ncbi.nlm.nih.gov/). Fungi were identified based on top BLAST results (lowest e-value, highest score, and greatest similarity).

Inoculation experiments. Seven of the most frequently isolated fungi (Botryosphaeria obtusa [Bo-Tt1], Fusarium cf. lateritium [Fl-Tt1], F. solani species complex [Fs-Tt1], Fusarium sp. 1 [Fsp1], Fusarium sp. 2 [Fsp-2], Lasiodiplodia theobromae, and Pestalotiopsis sp.) were used in inoculation experiments with potted, seed-grown T. taxifolia provided by the Atlanta Botanical Garden. For all three inoculation experiments (Table 1), inoculation points were made on each plant by making a wound using a sterile singleedge blade to make a vertical slit under the bark approximately 10 $\times 5 \mathrm{~mm}$ in size. The inoculum, a mycelium plug approximately 5 $\mathrm{mm}^{2}$, was inserted into the wound, which was wrapped in Parafilm. For mock-inoculated plants, wounds were made in the same manner, but sterile PDA plugs were used instead of mycelium plugs. The plants were maintained in a growth chamber with 16-h day length and temperatures of $25^{\circ} \mathrm{C}$ (light) and $18^{\circ} \mathrm{C}$ (dark) for 6 months following inoculation. For inoculation experiment 1 (IE1), one isolate of all species were used to inoculate the stems of one plant each of 2-year-old seedlings (average height approximately $25 \mathrm{~cm}$ ). One mock-inoculation was done on a separate plant as a control (Table 1). Each inoculation point was made on each plant at approximately $5 \mathrm{~cm}$ above the ground line. The Parafilm was removed after 2 weeks, and plants were monitored for symptom development at weekly intervals. Cankers were measured 3 months following inoculation, and percent stem circumference cankered was determined and mortality was measured after 6 months.

In inoculation experiment 2 (IE2), three different isolates of Fsp-1 were used (NRRL $54152=542$, NRRL $54154=587$, and NRRL $54155=596)$ to verify results obtained in IE1. Despite causing a canker in experiment IE1, FSSC isolate Fs-Tt1 was not used in subsequent experiments because it was infrequently isolated from cankers in the field $(<1 \%)$ and was not considered a likely candidate causal agent. All of the methods were the same, except a total of six plants were inoculated with two replicates per isolate. One mock-inoculation on a separate plant was included as a control (Table 1).

Inoculation experiment 3 (IE3) was performed using plants of two different sizes: 2-year-old seedlings as used before (average height $=27 \mathrm{~cm}$; average stem diameter $=0.6 \mathrm{~cm}$ ), and larger saplings, approximately 5 years old (average height of $89 \mathrm{~cm}$ and average stem diameter of $1.2 \mathrm{~cm}$ ). The larger saplings approximate the size of the trees re-sprouting and displaying canker symptoms in the field. Seven different isolates of Fsp-1 were used to inoculate plants (Torreya isolates listed in Table 2). Each isolate was inoculated onto one plant of the smaller size and two plants each of the larger size with three inoculation points on each plant for a total of nine inoculations per isolate. Two plants, one of each size, were mock inoculated (three inoculations per plant as described above) and served as controls (Table 1). Inoculation points on the smaller plants were distanced approximately $3 \mathrm{~cm}$ apart on the stems starting at $2.5 \mathrm{~cm}$ above ground line (and spiraling up the stem) and 5 $\mathrm{cm}$ apart on the larger plants starting at $10 \mathrm{~cm}$ above ground line. In addition to percent stem circumference girdled for each canker, mortality was assessed after 6 months.

Molecular phylogenetics. Isolates of Fsp-1 were cultured in yeast-malt broth for 2 to 3 days at $24^{\circ} \mathrm{C}$, after which total genomic DNA was isolated from freeze-dried mycelium using a hexadecyltrimethyl-ammonium bromide (Sigma-Aldrich, St. Louis, MO) protocol published previously (10). Seven isolates of the novel Fusarium sp.-1 (Fsp-1) of T. taxifolia (NRRL 54149-54155; Table 2) were characterized genetically by analyzing DNA sequences of the nuclear ribosomal internal transcribed spacer region (ITS rDNA), and partial sequences of translation elongation factor ( $E F$ $1 \alpha)$ and RNA polymerase second largest subunit (RPB2). The ITS rDNA region was PCR amplified and sequenced with primers ITS1> TCCGTAGGTGAACCTGCGG and ITS4> TCCTCC GCTTATTGATATGC; $E F-1 \alpha$ was PCR amplified with primers EF-1> ATGGGTAAGGARGACAAGAC and EF-2> GGARGT ACCAGTSATCATG and sequenced with EF-3> GTAAGG AGGASAAGACTCACC and EF-22T> AGGAACCCTTAC CGAGCTC; and RPB2 was PCR amplified and sequenced as two contiguous fragments using primers 5f2> GGGGWGAYCAGA

Table 1. Numbers of seedlings and treatments in inoculation experiments

\begin{tabular}{lccccc}
\hline Experiment no. & Total plants & $\begin{array}{c}\text { No. inoculated } \\
\text { with Fsp-1 }\end{array}$ & $\begin{array}{c}\text { No. Fsp-1 } \\
\text { isolates used }\end{array}$ & $\begin{array}{c}\text { No. inoculated } \\
\text { with other fungi }\end{array}$ & $\begin{array}{c}\text { No. mock- } \\
\text { inoculated }\end{array}$ \\
\hline IE1 & 8 & 1 & 1 & 6 & 1 \\
IE2 & 7 & 6 & 3 & 0 & 1 \\
IE3 & 16 & 14 & 7 & 0 & 2 \\
\hline
\end{tabular}

634 Plant Disease /Vol. 95 No. 6 
AGAAGGC $\times 7 \mathrm{cr}>$ CCCATRGCTTGYTTRCCCAT and 7cf $>$ ATGGGYAARCAAGCYATGGG $\times 11 \mathrm{ar}>$ GCRTGGATCTTR TCRTCSACC as previously described $(10,11,14,26)$. Platinum Taq DNA polymerase (Invitrogen Life Technologies, Carlsbad, CA) was used in all PCR reactions. Following PCR amplification, amplicons were sized by gel electrophoresis in $1.5 \%$ agarose gels (Invitrogen) run in $1 \times$ TAE buffer (15), after which they were stained with ethidium bromide and visualized over a UV transilluminator. Prior to sequencing with Applied Biosystems BigDye version 3.1 Terminator reaction mix (ABI, Emeryville, CA), amplicons were purified using Montage ${ }_{96}$ filter plates (Millipore Corp., Billerica, MA). Sequencing reaction mixes were conducted in a $10-\mu \mathrm{l}$ volume and contained $2 \mu \mathrm{l}$ of ABI BigDye version 3.1-terminator reaction mix, 2 to 4 pmol of a sequencing primer, and approximately $50 \mathrm{ng}$ of amplicon (10). Sequencing reaction mixes were purified using ABI XTerminator and then run on an ABI 3730 automated sequencer. Sequence chromatograms were edited for accuracy and aligned with Sequencher version 4.9 (Gene Codes, Ann Arbor, MI) prior to being exported as NEXUS files for subsequent analyses.

To assess the genetic diversity of the Florida torreya pathogen, we conducted phylogenetic analyses of the aligned partial $E F-1 \alpha$ and $R P B 2$ gene sequences employing maximum parsimony in PAUP (ver. 4.0b10; Sinauer Associates, Inc., Sunderland, MA; 24) and maximum likelihood in GARLI (ver. 0.951; 27). Maximum parsimony (MP) analyses were conducted in PAUP using the branch-and-bound option for an exact solution. The general-timereversible model with a proportion of invariant sites and gamma distributed rate heterogeneity was employed as the model of nucleotide substitution when using maximum likelihood (ML) as the optimality criterion. To investigate evolutionary relationships, $R P B 2$ sequences were obtained for five Fsp- 1 isolates and 19 additional phylogenetically diverse fusaria. Over half of the latter were represented by fusaria reported to be tree pathogens (6,9; Table 2). The best ML tree, based on 10 independent analyses of the RPB2 dataset, yielded a log-likelihood of -9930.87 (Fig. 1). Clade support was assessed by 1,000 MP and ML bootstrap pseudoreplicates of the data $(24,27)$. DNA sequences generated in this study have been deposited in GenBank under accession numbers HM068337HM068363.

\section{Results}

Field surveys. A total of 225 trees were located on eight sites with an average of 28 trees and a range of 15 to 47 trees per site. Average height and diameter at ground line among all eight sites were $118.5 \mathrm{~cm}$ and $1.9 \mathrm{~cm}$, respectively. Average height ranged from 77.7 to $262.6 \mathrm{~cm}$, and average DGL ranged from 0.87 to 4.4 $\mathrm{cm}$. Canker incidence ranged from 71 to $100 \%$ depending on site (Figs. 1 and 2) with an average incidence of 93.4\%. However, means for canker incidence were only statistically significant between the TNC Sweetwater Tract and all other sites (at the $P<$ 0.05 level; see Fig. 2).

Isolation and tentative identification of fungi. Samples were collected from cankers from a total of $46(20 \%$ of the currently known and surveyed population) trees from three sites (Torreya State Park, TNC-Sweetwater Tract, and TNC-Aspalaga Tract) representing a total of 150 samples. From these samples, nuclear ribosomal ITS rDNA sequences were obtained for 115 isolates. These sequences were used to query the GenBank database to identify the isolates. The most frequently isolated species appeared to represent a novel unidentified Fusarium species (28.7\% of all isolates and $44.0 \%$ of all sampled trees), designated Fsp-1, based on the results of the BLASTn searches (e-values $>0.0$ ). Unidentified fungi constituted the next most common group (21.7\% of all isolates and $40.3 \%$ of all sampled trees), followed by saprophytes (22.5\% of all isolates and $50.0 \%$ of all sampled trees) and Pestalotiopsis spp. (10.8\% of all isolates and $30.4 \%$ of all sampled trees). The remaining isolates were identified as known or potential pathogens (B. obtusa, F. cf. lateritium, members of the FSSC [12], unidentified Fusarium sp-2 [Fsp-2], L. theobromae) but constituted a low percentage $(3.9 \%$ of all isolates and only $10.9 \%$ of all sampled trees).

For the Torreya State Park samples, cankers from 31 trees were sampled, resulting in 91 isolates, with 78 being successfully se-

Table 2. Isolates used in the phylogenetic analysis

\begin{tabular}{|c|c|c|c|c|}
\hline NRRL no. ${ }^{\mathrm{a}}$ & Equivalent no. ${ }^{\text {b }}$ & Fusarium species ${ }^{c}$ & Host/substrate & Geographic origin \\
\hline 13622 & FRC L-55 & Fusarium cf. lateritium & Ulmus americana & LA-USA \\
\hline 20956 & CBS 123670 & Fusarium verticillioides & Zea mays & CA-USA \\
\hline 22161 & ATCC 18692 & FSSC 13-a (Fusarium solani f. sp. robiniae) & Robinia pseudoacacia & Japan \\
\hline 22163 & ATCC 18690 & FSSC 22-a (Fusarium solani f. sp. xanthoxyli) & Xanthoxylum piperitum & Japan \\
\hline 22230 & ATCC 44934 & FSSC 17-b (Fusarium solani f. sp. mori) & Morus alba & Japan \\
\hline 22316 & ATCC 66906 & Fusarium staphyleae & Staphylea trifolia & NJ-USA \\
\hline 22944 & CBS 217.76 & Fusarium proliferatum & Cymbidium sp. & Germany \\
\hline 25226 & BBA 69662 & Fusarium mangiferae & Mangifera indica & India \\
\hline 25331 & CBS 405.97 & Fusarium circinatum & Pinus radiata & CA-USA \\
\hline 25486 & CBS 258.52 & Fusarium xylarioides & Coffea sp. & Ivory Coast \\
\hline 28387 & PD 90/1377 & Fusarium commune & Unknown & The Netherlands \\
\hline 31011 & BBA 69079 & FIESC 12-a (Fusarium sp.) & Thuja sp. & Germany \\
\hline 31041 & LI \#95 & Fusarium virguliforme & Glycine max & IL-USA \\
\hline 31084 & PH-1 = CBS 123657 & Fusarium graminearum & Zea mays & MI-USA \\
\hline 34936 & CBS 123668 & Fusarium oxysporum f. sp. lycopersici & Solanum lycopersicum & The Netherlands \\
\hline 36148 & CBS 109638 & Fusarium buxicola & Buxus sp. & Belgium \\
\hline 36575 & CBS 976.97 & FIESC 20-b (Fusarium sp.) & Juniperus chinensis & HI-USA \\
\hline 37021 & FRC L-0110 & Fusarium cf. lateritium & Coffea $\mathrm{sp}$ & New Guinea \\
\hline 45880 & VanEtten 77-13-4 & FSSC 11-c (Fusarium solani f. sp. pisi) & Pisum sativum & Unknown \\
\hline 54149 & JAS \#481 (5005-08 canker) & Fusarium sp. (Fsp-1) & Torreya taxifolia & FL-USA (Aspalaga) \\
\hline 54150 & JAS \#499 (4005-08 recently dead) & Fusarium sp. (Fsp-1) & Torreya taxifolia & FL-USA (Gregory House) \\
\hline 54151 & JAS \#510 (5003-08 shoot dieback) & Fusarium sp. (Fsp-1) & Torreya taxifolia & FL-USA (Aspalaga) \\
\hline 54152 & JAS \#542 (5006-09 canker) & Fusarium sp. (Fsp-1) & Torreya taxifolia & FL-USA (Aspalaga) \\
\hline 54153 & JAS \#545 (5003-08 canker) & Fusarium sp. (Fsp-1) & Torreya taxifolia & FL-USA (Aspalaga) \\
\hline 54154 & JAS \#587 (4008-08 canker) & Fusarium sp. (Fsp-1) & Torreya taxifolia & FL-USA (Gregory House) \\
\hline 54155 & JAS \#596 (4025-09 canker) & Fusarium sp. (Fsp-1) & Torreya taxifolia & FL-USA (Gregory House) \\
\hline
\end{tabular}

a NRRL, Agricultural Research Service Culture Collection, Peoria, IL.

b ATCC, American Type Culture Collection, Manassas, VA; BBA, Biologische Bundesanstalt für Land-und Forstwirtschaft, Institute für Mikrobiologie, Berlin, Germany; CBS, CBS-KNAW Fungal Biodiversity Center, Utrecht, The Netherlands; FRC, Fusarium Research Center, Department of Plant Pathology, The Pennsylvania State University, University Park, PA; JAS, Jason A. Smith, University of Florida, Gainesville, FL.

c Strains of formae speciales (f. sp.) within the Fusarium solani species complex (FSSC) represent four phylogenetically distinct species. NRRL 13622 and 37021 are listed as Fusarium cf. lateritium because it is unclear which of these two species, if any, is authentic for this species. 
quenced (85.7\%). The most common species isolated was Fsp-1, isolated from $28.5 \%$ of all samples and $51.6 \%$ of all trees. This was followed by Pestalotiopsis sp. at $8.8 \%$ of all samples and $22.6 \%$ of all trees sampled. The remainder of the isolates could not be identified based on rDNA-ITS sequences $(23.2 \%$ of all samples and $70.9 \%$ of all trees) or were considered to be nonpathogenic fungi (24.2\% of all samples and $54.4 \%$ of all trees). A second unidentified Fusarium species (Fsp-2) based on BLASTn searches comprised $1.0 \%$ of all samples and $3.2 \%$ of all trees sampled.

Cankers from five trees were sampled at the TNC-Aspalaga Tract, resulting in 14 isolates from which ITS rDNA sequence data were obtained. The most common species isolated were Fsp-1 (21.4\% of all samples and $14.3 \%$ of all trees sampled) and Pestalotiopsis sp. (21.4\% of all samples and $14.3 \%$ of all trees sampled). The remainder of the isolates could not be identified using the rDNA-ITS sequence data (42.9\% of all samples and $100 \%$ of all trees sampled) or appeared to represent saprophytic species $(14.3 \%$ of all samples and trees sampled).

Cankers from 10 trees were sampled at the TNC-Sweetwater tract, from which ITS rDNA sequence data were obtained from the 24 isolates recovered. The most commonly isolated species was Fsp-1, isolated from $33.4 \%$ of all samples and $40.0 \%$ of all trees sampled. This was followed by Pestalotiopsis sp. at $20.9 \%$ of all samples and $30.0 \%$ of all trees sampled. The remainder of the isolates could not be identified to species using the ITS rDNA sequence data (16.6\% of all samples and $40.0 \%$ of all trees sampled), or they appeared to represent saprophytes $(12.5 \%$ of all samples and $30.0 \%$ of all trees sampled). The rest of the samples were identified as known plant pathogens (B. obtusa, $F$. cf. lateritium, members of the FSSC [12], and L. theobromae) (16.6\% of all isolates and $30.0 \%$ of all sampled trees), but not found at other locations.

Inoculation experiments. No cankers formed following inoculation with B. obtusa, F. cf. lateritium, Fusarium sp-2 (Fsp-2), L. theobromae, and Pestalotiopsis sp. in IE1. The FSSC isolate and Fusarium sp-1 (Fsp-1) caused cankers (\% stem girdle; \% SG = $100 \%$ ) that caused mortality above the inoculation point after 6 months (Fig. 3C and D). Since Fs-Tt1 was infrequently recovered in this study, additional experiments focused on Fsp-1. In IE2, all three isolates of Fsp-1 induced cankers on all plants. Cankers were not observed on the negative controls. The average \% SG for isolate NRRL $54152=542(65.0 \%)$, for NRRL $54154=587(65.0 \%)$, and for NRRL $54155=596(80.0 \%)$. One of each of the two replicates of isolates NRRL 54154 and 54155 caused mortality after 6 months. Sporodochia of Fsp-1 were observed on the cankered tissue at approximately 4 months postinoculation. In IE3, all three isolates of Fsp-1 tested caused cankers on all plants inoculated; cankers were not induced on the plants included as negative controls. The average \% SG for all isolates inoculated onto the larger plants was $16.9 \%$ (control $=0 \%$ ) and on the smaller plants was $84.1 \%$ (control $=0.0 \%$ ). Isolates NRRL $54149=481$ and NRRL $54152=542$ both caused sapling mortality after 6 months. After 4

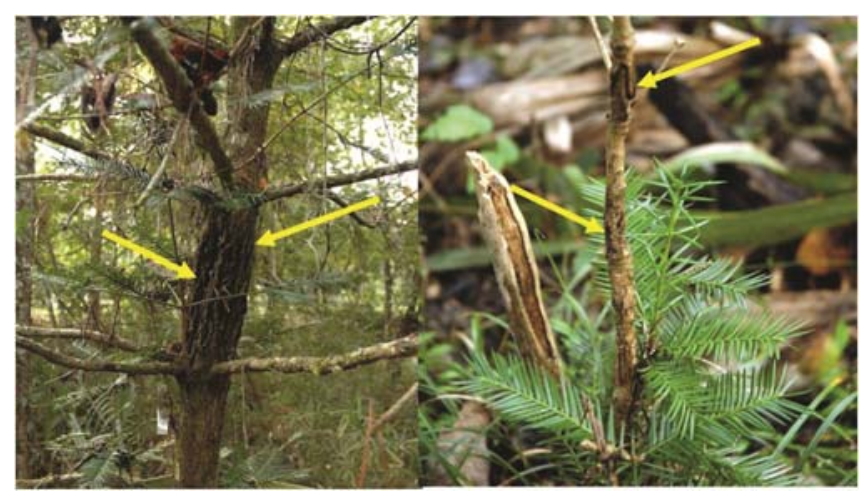

Fig. 1. Typical stem cankers (yellow arrows) observed on main stem of tree and basal sprouts of Torreya taxifolia at natural sites. months, cankers that formed from the three individual inoculation points began to coalesce to form large single cankers (Fig. 3A and B). For all inoculation experiments, Fsp-1was recovered from the advancing canker margin on each plant at the end of the experiment. The identity of the fungi recovered was determined to be Fsp-1 based on analyses of their ITS rDNA sequence.

Molecular phylogenetics. DNA sequence data were obtained from portions of three nuclear genes to identify the Florida torreya pathogen (Fsp-1) and to characterize its genetic diversity (Table 2). ITS rDNA sequences of the six isolates sequenced (NRRL 5414954151, 54153-54155) were identical and yielded an alignment of 453 nucleotide positions. A search of GenBank (http://www.ncbi. nlm.nih.gov/), using one of the ITS rDNA sequences as the query, identified Fusarium lateritium BBA 65675 (AY188920, 96\% identity), F. buharicum (FBU34581, 97\% identity), and Fusarium sp. IP-87 (DQ780424, 97\% identity) as the best matches. Partial EF$1 \alpha$ sequences of the seven isolates (NRRL 54149-54155) yielded an alignment of $689 \mathrm{bp}$. A branch-and-bound search of the $E F-1 \alpha$ dataset identified four equally most parsimonious trees four steps in length. Five unique haplotypes were identified among the seven sequences (Fig. 4). BLAST searches of GenBank and the FUSARIUM-ID database (http://isolate.fusariumdb.org/index.php; 5), using a partial $E F-1 \alpha$ sequence as the query, failed to identify any sequences producing significant alignments. This query identified an $E F-1 \alpha$ sequence of $F$. redolens NRRL 52619 (GU250581) with the best maximum identity, but at only $86 \%$. Similar BLAST searches of GenBank, using a partial RPB2 sequence as the query, also identified sequences with a maximum identity of only $86 \%$ as the top hits (ex., F. concolor EF470115 and F. brachygibbosum GO505482). The results of these three BLAST searches, coupled with comparisons of the partial $E F-1 \alpha$ and $R P B 2$ gene sequences with more inclusive fusarial databases of these two genes $(K$. O'Donnell, unpublished), strongly indicated that the Florida torreya pathogen represented a novel species of Fusarium.

To assess phylogenetic relationships of the Florida torreya pathogen within Fusarium, MP and ML analyses were conducted on partial $R P B 2$ sequences (1,772 bp alignment) of five Fsp-1 isolates together with a phylogenetically diverse set of 19 Fusarium spp.; over half of the latter have been reported to be tree pathogens (Table 2; Fig. 5). The results of these analyses were highly concordant in placing the Florida torreya pathogen as a novel phylogenetically distinct species representing one of the earliest diverging lineages within the Gibberella clade of Fusarium.

\section{Discussion}

Field studies indicate that the existing Florida torreya population is severely affected by canker disease. However, linking any current threat, including CDFT, with the historical decline of this critically endangered species is difficult to accomplish. Although several authors hypothesized the role of a pathogen in the initial decline of Florida torreya $(2,3,22)$, no pathogen was conclusively demonstrated to be the cause of decline. The rapid die off and subsequent windthrow of dead trees (21) suggests the involvement of a root pathogen (e.g., Phytophthora cinnamomi); however, no root pathogen has been shown to cause significant damage to

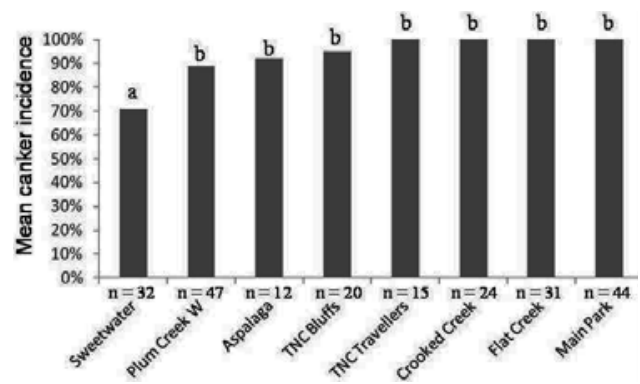

Fig. 2. Canker incidence in eight Florida torreya sites surveyed during 2008 to 2010. Letters above bars represent homogenous subsets (Duncan's test, $P<0.05$ ). 

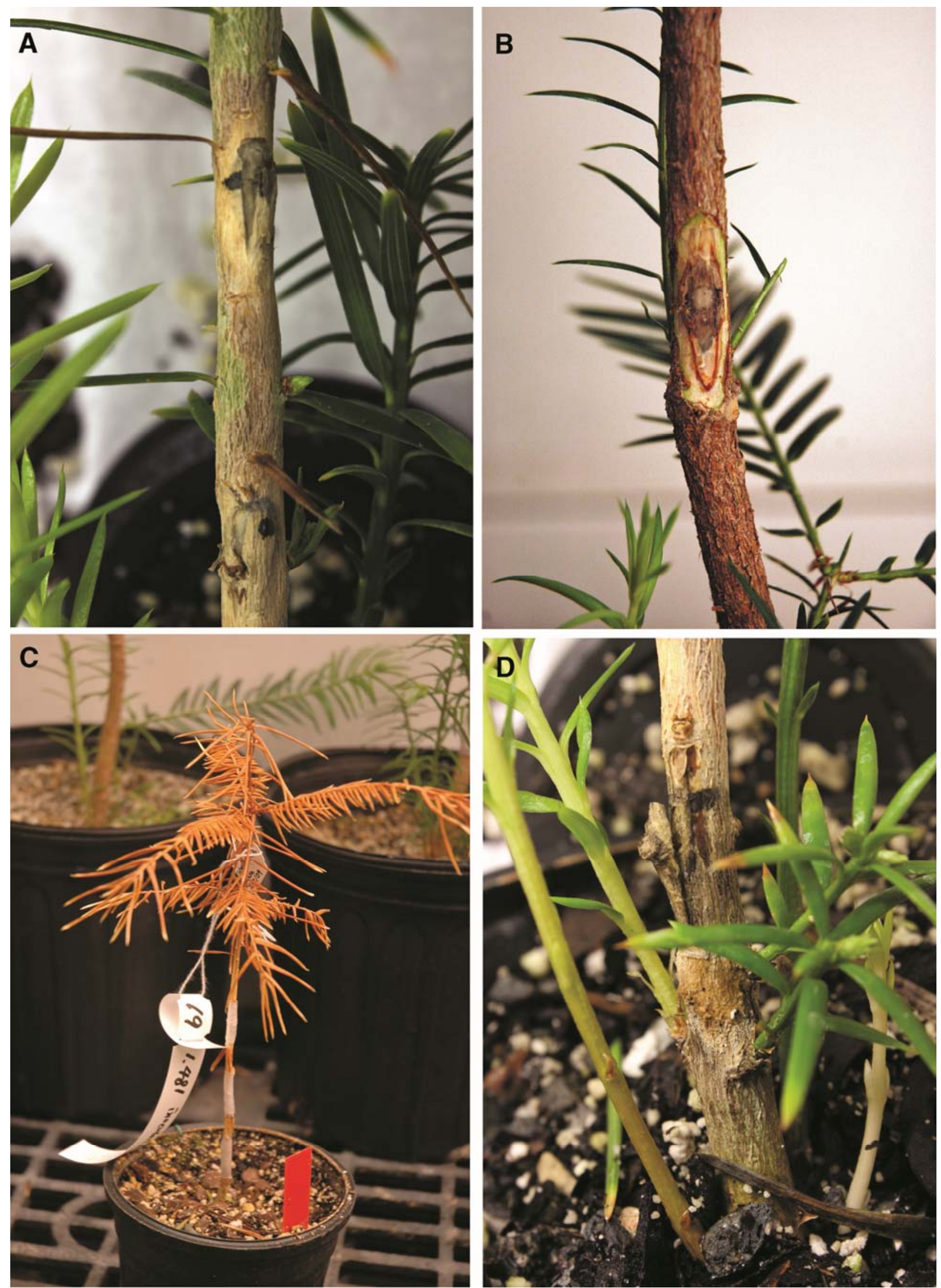

Fig. 3. Symptoms on cultivated plants inoculated with Fusarium sp. (Fsp-1). A, Cankers coalescing; B, bark scraped away to reveal lesion; C, mortality of inoculated seedling D, seedling with stem mortality above inoculation point and basal sprouting. Symptoms observed at 4 weeks (A and B) and 6 weeks (C and D) postinoculation, respectively. 


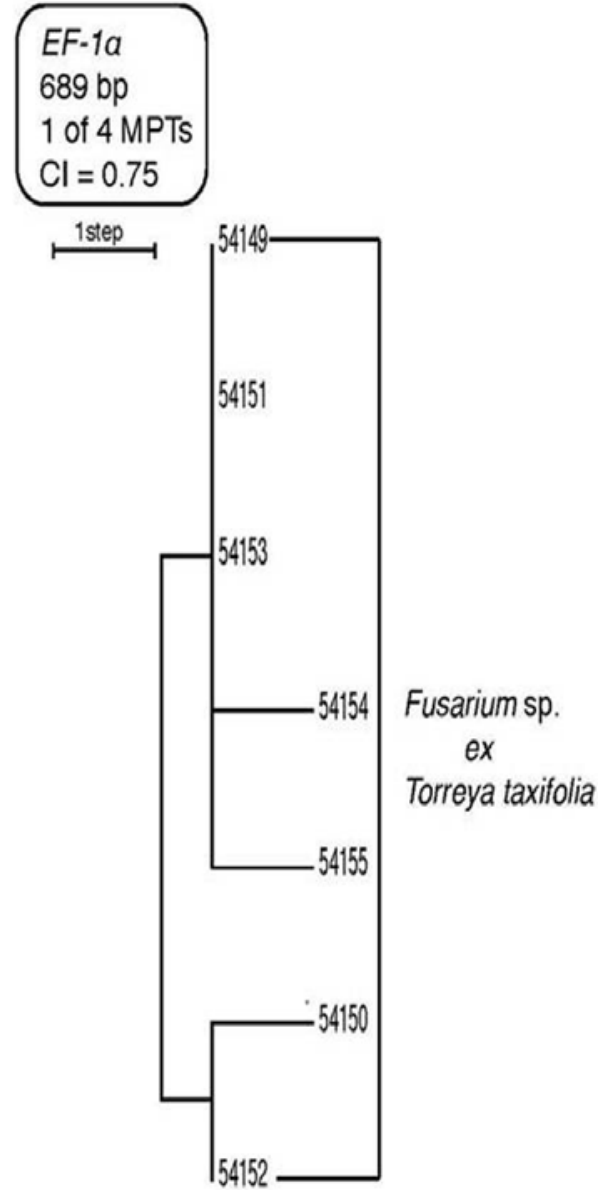

Fig. 4. One of four most-parsimonious phylograms inferred for partial $E F-1 \alpha$ gene sequences for seven isolates of the Torreya taxifolia (Florida torreya) pathogen. Five unique, but closely related, haplotypes are represented in the midpoint-rooted tree.

Florida torreya. Moreover, the fact that basal sprouts frequently develop from older root systems suggests that the roots are not currently affected by disease.

Inoculation experiments verify that CDFT is caused by an undescribed Fusarium sp. Although Fusarium spp. have been implicated as causal agents of disease of Florida torreya in the past, none has been demonstrated to either induce cankers and stem mortality or cause symptoms that are similar to those observed in the field. A pathogen reported as F. lateritium caused leaf spots on Florida torreya, but apparently not cankers (3). The novel Fusarium species has not been detected in previous pathology studies of Florida torreya. However, because published studies on CDFT did not include molecular phylogenetic data, it is possible that Fsp-1 was misidentified as a described species using morphological species recognition.

Analyses of multilocus DNA sequence data, which included BLAST searches of GenBank and the FUSARIUM-ID databases (5), phylogenetic analyses of partial $R P B 2$ gene sequences, and DNA sequence comparisons with more inclusive $E F-1 \alpha$ and $R P B 2$ gene sequence databases (K. O'Donnell, unpublished data), strongly suggest the Florida torreya pathogen represents a novel, phylogenetically distinct species within Fusarium (25). Phylogenetic placement of this novel pathogen as one of the earliest diverging lineages within the Gibberella clade was greatly facilitated by the use of partial $R P B 2$ sequence data, which has a significant advantage over ITS rDNA and partial $E F-1 \alpha$ data, in that it can be easily aligned across the phylogenetic breadth of Fusarium (11). ITS rDNA sequence data have low utility within Fusarium because highly divergent paralogs or xenologs have been reported within the Gibberella fujikuroi and $F$. oxysporum species complexes and because it contains relatively little phylogenetic signal (10). By

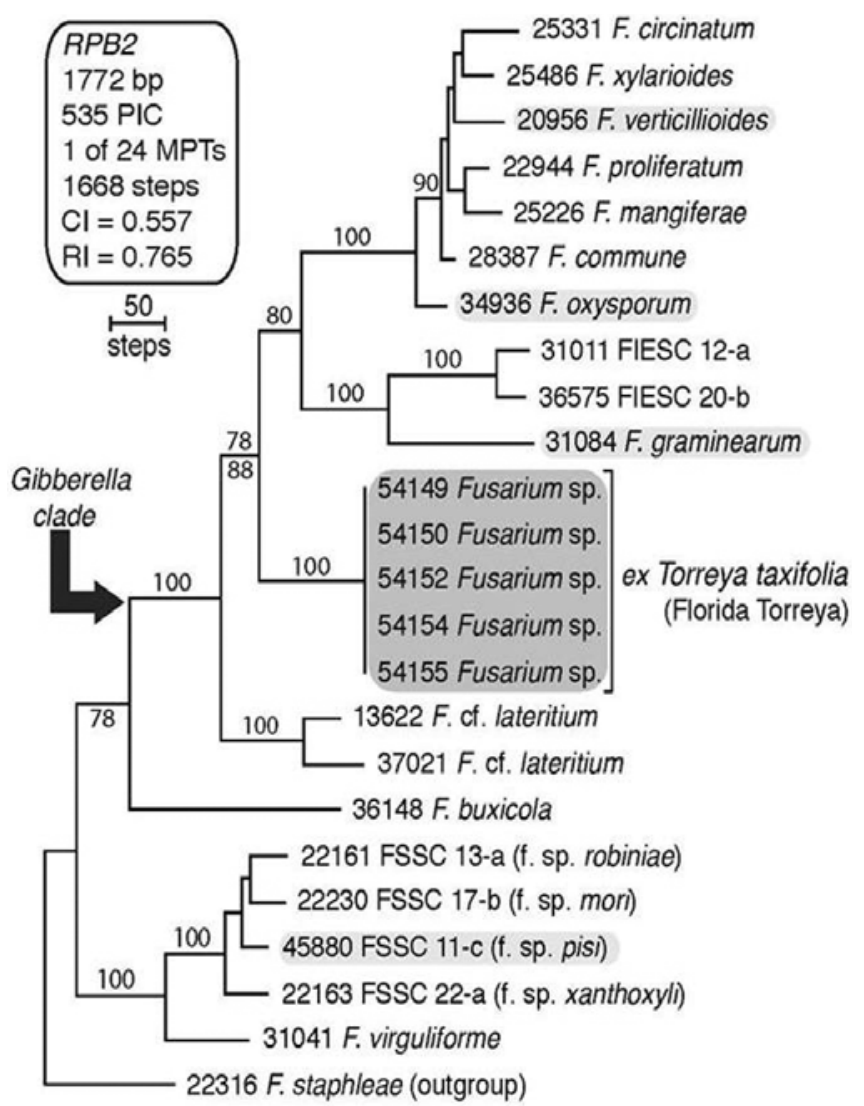

Fig. 5. One of 24 equally most-parsimonious trees inferred from partial $R P B 2$ gene sequences for 24 fusaria, including five isolates of the Florida torreya pathogen (highlighted in dark gray). The whole genome sequence of the four fusaria highlighted in light gray is publically available. Note that the Florida torreya isolates form a phylogenetically distinct lineage, representing one of the earliest divergences within the Gibberella clade of Fusarium.

way of contrast, $R P B 2$ sequence data are highly informative phylogenetically, as evidenced by the large number of parsimony informative characters in the dataset analyzed in the present study (Fig. 1) and in previously published studies of other fusaria $(11,12,13)$.

Florida torreya faces numerous challenges to its future survival in its natural habitat. In addition to the canker disease, deer routinely cause damage to stems from antler rubbing. It is unclear whether they are attracted by the tree's aroma or seek out Florida torreya for some other unknown reason. Whether the wounds caused by deer serve as infection courts for pathogens, including the new Fusarium sp. (Fsp-1), is unclear and warrants further study. Additionally, since lesions on the larger plants in IE3 resulted in less stem girdling and no mortality, the host response to infection, particularly under different stress conditions, needs to be investigated. In addition to more research on the biology and management of CDFT, more work is needed to assess the various factors involved in decline of Florida torreya and how the species can be protected from extinction.

\section{Acknowledgments}

We thank the Florida Parks Department staff and numerous volunteers who were instrumental in carrying out the surveys for Florida torreya. We also thank Stacy Sink for generating the DNA sequence data reported in this study and Nathane Orwig for collecting the DNA sequence data in the NCAUR DNA core facility. Mention of firm names or trade products does not imply that they are endorsed or recommended by the U.S. Department of Agriculture over other firms or similar products not mentioned.

\section{Literature Cited}

1. Alfieri, S. A., Jr., Martinez, A. P., and Wehlburg, C. 1967. Stem and needle blight of Florida torreya (Torreya taxifolia Arn.). Proc. Fla. State Hortic. Soc. 80:428-431. 
2. Alfieri, S. A., Jr., Schoulties, C. L., Langdon, K. R., and El-Gholl, N. E. 1987. Leaf and stem disease of Torreya taxifolia in Florida. Plant Pathology Circ. No. 291. Florida Department of Agriculture and Consumer Service, Division of Plant Industry.

3. El-Gholl, N. E. 1985. Fusarium lateritium causing needle spots on Torreya taxifolia in Florida. Plant Dis. 69:905.

4. Farjon, A. 2010. A Handbook of the World's Conifers. Brill Academic Publishers, Leiden, Netherlands.

5. Geiser, D. M., del Mar Jiménez-Gasco, M., Kang, S., Makalowska, I., Veeraraghavan, N., Ward, T. J., Zhang, N., Kuldau, G. A., and O'Donnell, K. 2004. FUSARIUM-ID v.1.0: A DNA sequence database for identifying Fusarium. Eur. J. Plant Pathol. 110:473-479.

6. Gerlach, W., and Nirenberg, H. 1982. The genus Fusarium - A pictorial atlas. Mitt. Biol. Bundesanst. Land-Forstwirtsch, Berlin-Dahlem 209:1-406.

7. Godfrey, R. K., and Kurz, H. 1962. The Florida torreya destined for extinction. Science 136:900-902.

8. Lee, J. C., Yang, X., Schwartz, M., Strobel, G., and Clardy, J. 1995. The relationship between an endangered North American tree and an endophytic fungus. Chem. Biol. 2:721-727.

9. Leslie, J. F., and Summerell, B. A. 2006. The Fusarium Laboratory Manual. Blackwell Publ., Ames, IA.

10. O’Donnell, K., Cigelnik, E., and Nirenberg, H. 1998. Molecular systematics and phylogeography of the Gibberella fujikuroi species complex. Mycologia 90:465-493.

11. O’Donnell, K., Sarver, B. A. J., Brandt, M., Chang, D. C., Noble-Wang, J., Park, B. J., Sutton, D. A., Benjamin, L., Lindsley, M., Padhye, A., Geiser, D. M., and Ward, T. J. 2007. Phylogenetic diversity and microsphere arraybased genotyping of human pathogenic fusaria, including isolates from the multistate contact lens-associated U.S. keratitis outbreaks of 2005 and 2006. J. Clin. Microbiol. 45:2235-2248.

12. O'Donnell, K., Sutton, D. A., Fothergill, A., McCarthy, D., Rinaldi, M. G., Brandt, M. E., Zhang, N., and Geiser, D. M. 2008. Molecular phylogenetic diversity, multilocus haplotype nomenclature, and in vitro antifungal resistance within the Fusarium solani species complex. J. Clin. Microbiol. 46:2477-2490

13. O’Donnell, K., Sutton, D. A., Rinaldi, M. G., Gueidan, C., Crous, P. W., and Geiser, D. M. 2009. Novel multilocus sequence typing scheme reveals high genetic diversity of human pathogenic members of the Fusarium incarnatum- $F$. equiseti and $F$. chlamydosporum species complexes within the United States. J. Clin. Microbiol. 47:3851-3861.
14. O'Donnell, K., Ward, T. J., Geiser, D. M., Kistler, H. C., and Aoki, T. 2004. Genealogical concordance between the mating type locus and seven other nuclear genes supports formal recognition of nine phylogenetically distinct species within the Fusarium graminearum species complex. Fungal Genet. Biol. 41:600-623.

15. Sambrook, J., Fritsch, E. F., and Maniatis, T. 1989. Molecular Cloning: A Laboratory Manual. Cold Spring Harbor Laboratory, Cold Spring Harbor, NY.

16. Schwartz, M. W. 1993. Allozyme variation of the endangered Florida torreya (Torreya taxifolia). Can. J. For. Res. 23:2598-2602.

17. Schwartz, M. W., and Hermann, S. 1993. The continuing population decline of Torreya taxifolia Arn. Bull. Torrey Bot. Club 120:275-286.

18. Schwartz, M. W., and Hermann, S. M. 1999. Is slow growth of the endangered Torreya taxifolia (Arn.) normal? J. Torrey Bot. Soc. 126:307-312.

19. Schwartz, M. W., Hermann, S. M., and van Mantgem, P. J. 2000. Population persistence in Florida torreya: Comparing modeled projections of a declining coniferous tree. Conserv. Biol. 14:1023-1033.

20. Schwartz, M. W, Hermann, S. M., and van Mantgem, P. J. 2000. Estimating the magnitude of decline of the Florida torreya (Torreya taxifolia Arn.). Biol. Conserv. 95:77-84

21. Schwartz, M. W., Hermann, S. M., and Vogel, C. 1995. The catastrophic loss of Torreya taxifolia: assessing environmental induction of disease hypotheses. Ecol. Appl. 5:501-516.

22. Schwartz, M. W., Porter, D. J., Hermann, S. M., and Strobel, G. 1996 Occurrence of Pestalotiopsis microspora on Torreya taxifolia in Florida. Plant Dis. 80:600.

23. Sinclair, W., and Lyon, H. H. 2005. Diseases of Trees and Shrubs. Cornell University, Ithaca, NY.

24. Swofford, D. L. 2002. PAUP*. Phylogenetic analysis using parsimony (*and other methods), version 4.0b10. Sinauer Associates, Sunderland, MA

25. Taylor, J. W., Jacobson, D. J., Kroken, S., Kasuga, T., Geiser, D. M., Hibbett, D. S., and Fisher, M. C. 2000. Phylogenetic species recognition and species concepts in fungi. Fungal Genet. Biol. 31:21-32.

26. White, T. J., Bruns, T., Lee, S., and Taylor, J. 1990. Amplification and direct sequencing of fungal ribosomal RNA genes for phylogenetics. Pages 315322 in: PCR Protocols: A Guide to Methods and Applications. M. A. Innes, D. H. Gelfand, J. J. Sninsky, and T. J. White, eds. Academic Press, San Diego, CA.

27. Zwickl, D. J. 2006. Genetic algorithm approaches for the phylogenetic analysis of large biological sequence data sets under the maximum likelihood criterion. Ph.D. diss. University of Texas, Austin. 